\title{
Opioid usage trends in treatment - Trends from the field
}

\author{
Jeri Wheeler*1, Siobhan Morse ${ }^{2}$, Brian Bride ${ }^{3}$ \\ ${ }^{1}$ Foundations Recovery Network, United States \\ ${ }^{2}$ Universal Health Services, United States \\ ${ }^{3}$ Georgia State University, United States
}

Received: November 27, 2018

Accepted: December 27, 2018 Online Published: January 8, 2019

DOI: $10.5430 /$ ijh.v5n1p29

URL: https://doi.org/10.5430/ijh.v5n1p29

\begin{abstract}
Objective: As legislative changes limiting access to prescription opioids were enacted, the population of opioid use disorder patients seeking private residential treatment also changed. This study is designed to examine some of the specific changes that were observed between opioid used disorder patients entering treatment before and after the legislative restrictions were enacted. Study design: Retrospective cross-sectional cohort design.

Results: Significant changes from Group 1 (patients presenting for treatment in 2009-2011) to Group 2 (patients presenting for treatment in 2014) include a substantial decrease in the usage of prescription opiates. Alongside this reduction, a significant increase was shown in reported heroin abuse with concurrent polysubstance abuse (Cannabis, Amphetamines, and Sedatives), as well as noted employment and family issues.

Conclusions: The identified patient presenting to treatment for Opioid Use Disorder has changed over the last several years and treatment should reflect those changes. Not only has this disease become one of opioid usage but of polysubstance abuse and disruption in other areas of life as heroin usage becomes more prominent in patients.
\end{abstract}

Key Words: Opioid use disorder, Addiction, Co-occurring disorder, Heroin use, Recovery treatment

\section{INTRODUCTION}

Opioid Use Disorder has increased substantially over the last decade. The amount of opioids prescribed and sold in the United States has tripled since 1999 creating an epidemic that is interrupting American communities, families, and lives. Prescription opioids are the most significantly misused doctor prescribed substance, and have become increasing abused overtime. ${ }^{[1]}$ More than four times as many prescription painkillers were sold to pharmacies, hospitals, and doctors' offices in 2010 than a decade before. ${ }^{[2]}$ These numbers have resulted in over 350,000 opioid related deaths since that time, with a number that continues to climb today causing one of the largest crisis in American history. ${ }^{[3]}$

As opioid addiction numbers have increasingly grown over the years, federal authorities began to notice the risk of dependency and lethality among the population. Due to this observation legislation began to change, for example, with House Bill 93 in 2011 creating tighter regulations for pain killer prescriptions. Between 2011-2014, bills in 35 different states were enacted which impacted many aspects of the crisis from limiting supplies of opioids to changing in sentencing for those convicted of crimes of opioid use. ${ }^{[4]}$

*Correspondence: Jeri Wheeler; Email: jeri.wheeler@frnmail.com; Address: Foundations Recovery Network, United States. 
Many of these regulations drastically limited the availability of prescription opioids, leaving those with an opioid use disorder in a contentious situation. ${ }^{[5]}$ With this increased focus and resulting legislation limiting the accessibility of opioid prescriptions, the American population has seen a substantial increase in heroin usage. ${ }^{[6]}$ Along with the increased use of this street opiate has come increasing variability in the populations seeking treatment for opioid use disorders. Significant changes in lifestyle as well as substance use patterns have marked a notable shift in trends of those struggling with and presenting for treatment with an opioid use disorder. ${ }^{[3]}$

The purpose of this study was to evaluate the differences in opioid use disorder patients presenting to private, residential treatment for co-occurring substance use and mental health disorders prior to legislative changes (2009-2011) and following the changes (2014). Patient characteristics, such as drug use severity, frequency and drug of choice are important factors in determining programming strategies overall as well as individualizing care.

\section{MethodS}

This study utilized naturally occurring retrospective data from 1,825 adults enrolled in residential substance abuse and mental health treatment services between 2009 and 2014 in private, integrated residential treatment operated by Foundations Recovery Network (FRN), a division of Universal Health Services. Study participants were drawn from patients at FRN, a for-profit addictions recovery facility, attending residential treatment at facilities in Georgia, Tennessee, and California. All participants in this experiment gave consent to become part of this research project and all patients presenting to treatment at FRN were given an opportunity to give consent. A community-based Institutional Review Board approved the study protocol to assure the protection of Human Subjects.

Two naturally occurring groups of patients were examined. Group 1 consists of patients reporting with an opioid use disorder admitted between 2009-2011 ( $n=801)$ during the peak of the prescription drug use epidemic. ${ }^{[7]}$ Data collected between 2009 and 2011 concerned to the characteristics and outcomes of opioid use disorder patients with co-occurring mental health disorders seeking treatment in integrated residential care. Group 2 is comprised of data collected for the purpose of this study. Group 2 consists of patients reporting to treatment with an opioid use disorder admitted during 2014 ( $n=1,024)$, following the first legislation limiting the availability of prescription opioids. In this article, we compare the presenting characteristics of Group 1 to patients admitted to the same network of residential treatment programs during 2014 (Group 2).
Trained intake professionals at each facility described the study, obtained informed consent from participants, and collected study data within 72 hours of admission. Informed consent for participation in research was reviewed and approved by and Institution Review Board. The Addiction Severity Index (ASI) ${ }^{[8]}$ was used to measure addiction severity and recent substance use. More specifically, addiction severity was measured with the ASI's composite severity indices in each of seven potential problem areas that include: medical, employment, alcohol, drug, legal, family/social problems, and psychiatric symptoms. This scoring yields a score from 0-1 for each composite index, with higher scores indicating greater severity. Embedded in the ASI, as components of the alcohol and drug composite scores, are questions exploring recent substance use. For this specific study, we focused on specific ASI items that gathered information on participants' past month use of: any alcohol at all, alcohol to intoxication, heroin, prescription opiates, sedatives, cocaine, amphetamines, and cannabis.

In order to examine differences between the two admissions cohorts, chi-square analyses were conducted on dichotomous variables and independent (Student) $t$-tests were conducted on continuous variables.

\section{RESULTS}

The two groups were demographically similar in terms of gender and race $-63 \%$ male, and $93 \%$ white. The two groups had differentiated mean ages; Group 2 (mean $=29.5$ years) averaged three years younger than Group 1 (mean $=32.5$ years). As seen in Tables 1-2, Group 2 reported significantly higher ASI composite scores in the domains of employment (.497 vs. .415), alcohol (.322 vs. .249), and family/social (.444 vs. .344) and reported significantly lower ASI composite scores in the domains of drugs (.226 vs. .316), legal (.126 vs. .150), and psychiatric (.415 vs. .513). The cohorts reported similar medical composite scores. In addition, Group 2 reported significantly more days using amphetamines (4.17 vs. 1.33 ), cannabis (9.10 vs. 6.81), heroin (11.52 vs. 5.74), and sedatives (8.54 vs. 10.14). On the other hand, Group 2 reported fewer days using prescription opiates (11.84 vs. 14.56). Both cohorts reported similar use of alcohol, alcohol to intoxication, and cocaine.

\section{Discussion}

In looking at the intake data of opioid use disorder patients from two distinguished time points, we are able to examine results showing a significant increased consumption of heroin. Patients presenting for treatment in Group 2 are consuming heroin twice as often as those in Group 1, a group presenting to treatment just a few years prior. Along with

ISSN 2377-7338 E-ISSN 2377-7346 
this noted increase in the use of heroin at intake, we also see a significant decrease (about 33\% lower) in the amount of prescription opioids being abused in Group 2. From this observation, we can infer that heroin usage is becoming more prominent in patients admitted to private, residential treatment while prescription opioid usage is decelerating.

Table 1. Comparison of patients from pre-legislation (Group 1, 2009-2011) to post-legislation (Group 2, 2014) on addiction severity index composite scores and specific substance use questions at intake for residential treatment (standard deviations in parenthesis)

\begin{tabular}{llll}
\hline & $\begin{array}{l}\text { Group 1 } \\
(\mathbf{n}=\mathbf{8 0 1})\end{array}$ & $\begin{array}{l}\text { Group 2 } \\
(\mathbf{n}=\mathbf{1 , 0 2 4})\end{array}$ & $\boldsymbol{p}$ \\
\hline ASI Composite & & & \\
$\quad$ Medical & $.325(.38)$ & $.344(.36)$ & $\mathrm{ns}$ \\
Employment & $.415(.27)$ & $.497(.23)$ & $<.05$ \\
Alcohol & $.249(.32)$ & $.322(.31)$ & $<.05$ \\
Drug & $.316(.13)$ & $.226(.17)$ & $<.05$ \\
Legal & $.150(.24)$ & $.126(.21)$ & $<.05$ \\
Family & $.344(.27)$ & $.444(.58)$ & $<.05$ \\
Psychiatric & $.513(.199)$ & $.415(.20)$ & $<.05$ \\
Substance use & & & \\
Any Alcohol & $8.11(10.71)$ & $7.58(10.25)$ & $\mathrm{ns}$ \\
Alcohol to Intoxication & $6.15(9.91)$ & $5.89(9.57)$ & $\mathrm{ns}$ \\
Amphetamines & $1.33(5.17)$ & $4.17(8.58)$ & $<.05$ \\
Cannabis & $6.81(11.02)$ & $9.10(11.65)$ & $<.05$ \\
Cocaine & $3.31(7.36)$ & $2.98(6.99)$ & $\mathrm{ns}$ \\
Heroin & $5.74(10.32)$ & $11.52(12.95)$ & $<.05$ \\
Rx Opiates & $14.56(11.64)$ & $11.84(12.35)$ & $<.05$ \\
Sedatives & $6.11(10.14)$ & $8.54(10.98)$ & $<.05$ \\
\hline
\end{tabular}

Table 2. Demographic comparison of patients from pre-legislation (Group 1, 2009-2011) to post-legislation (Group 2, 2014) (standard deviations in parenthesis)

\begin{tabular}{llll}
\hline & $\begin{array}{l}\text { Group 1 } \\
(\mathbf{N = 8 0 1 )}\end{array}$ & $\begin{array}{l}\text { Group 2 } \\
(\mathbf{N = 1 , 0 2 4 )}\end{array}$ & $\boldsymbol{p}$ \\
\hline Age & $32.5(11.7)$ & $29.5(10.3)$ & $<.05$ \\
Gender & & & $\mathrm{ns}$ \\
$\quad$ Male & $60 \%$ & $66 \%$ & \\
$\quad$ Female & $40 \%$ & $34 \%$ & \\
Race & & & $\mathrm{ns}$ \\
White & $93 \%$ & $93 \%$ & \\
Other & $7 \%$ & $7 \%$ & \\
\hline
\end{tabular}

Alongside this increase use of heroin in Group 2, there is an examined paralleled increase in other illicit street drugs. We can examine that polysubstance usage is becoming a larger problem as users in treatment increasingly consume heroin, specifically with cannabis $(34 \%$ increase), sedatives $(40 \%$ increase), and amphetamines (214\% increase). This begs us to ask the question of what is influencing opioid users in the transition to heroin use and furthermore the exposure to a multitude of other substances in the comparison of Group 1 and Group 2. Could the environment in which heroin is obtained be a factor that promotes the exploration of polysubstance abuse in more recent patients? This uncovers a larger phenomenon inside of opioid use disorder treatment which now involves the integration of multiple substance use recovery and an increased severity of addiction. There are medications to aid in the recovery of opioid use disorder but there are limited options for medication regarding polysubstance abuse, making this type of dependence more likely to require additional intensive treatment covering a broader range of topics.

Looking over the ASI composite scores for these two groups we can see that there is a significant increase in reported family and employment issues in Group 2. Family systems research has shown that the entire family is affected by a member suffering from an opioid dependency. ${ }^{[9]}$ As an individual moves farther into an addiction, the risk of isolation steadily increases which might create a strain in the familial relationship. The stigma around illegal substance use as opposed to prescription opioids use could amplify family concern as well as potentially create a lack of recovery treatment interest or openness to communicate need for recovery treatment. ${ }^{[10]}$

Additionally, there are other possible implications for obstacles to recovery within heroin and polysubstance abuse. Other interesting implications could imply purchasing illegal drugs causing an increased exposure to dangerous and potentially traumatic situations. These implications are areas where treatment focus can better serve the population presenting with opioid use disorder if paid attention to. All of this information leads us to believe that opioid use disorder treatment should be multifaceted and all of these factors should be considered in individualized treatment for what is a growing and evolving crisis in many populations.

\section{Limitations}

The study used previously reported data by Bride BE et al. as a baseline for comparison of characteristics across a population. ${ }^{[7]}$ As well, due to the nature of private, insurancepaid treatment, it is possible that population of opioid-using persons seeking treatment has not changed, but that those accepted to residential treatment has been what changed. While this may limit the application of these results to the general population of opioid users and causality, it provides valuable information for administrators and program managers of insurance-based treatment and services. Patients in the 
second group may also differ from first group in ways that are unmeasured due to time, location, and staff of treatment facility. However, there is a limited amount of information published on the patient seeking private, residential care, and this provides insight into an important subset of the population at a critical time.

\section{Conclusions}

For many patients, prescription painkiller use may have been a triggering factor that began a painful journey to heroin use as well as exposure to polysubstance use and resulting other life issues. For patients attending private, residential treatment, this study finds that not only is the de-escalation of opiate use the primary focus of treatment for these individuals but our data shows areas such as relationships, development of support, career counseling, trauma and addressing polysubstance usage as important components to consider for Opioid Use Disorder treatment.

\section{CONFliCtS OF INTEREST DisClOSURE}

The authors declare no conflicts of interest.

\section{REFERENCES}

[1] SAMHSA. (2011, October 10). The Dual Diagnosis Capability in Addiction Treatment (DDCAT) Toolkit. June 26, 2018. Available from: http://www. samhsa.gov/co-occurring/ddcat/

[2] Centers for Disease Control and Prevention. Prescription Painkiller Overdoses in the US. 2011. Available from: https://www.cdc.go v/vitalsigns/painkilleroverdoses/index.html

[3] Centers for Disease Control and Prevention. Opioid Overdose. 2017. Available from: https://www.cdc.gov/drugoverdose/epide $\mathrm{mic} /$ index.html

[4] Ncsl.org - Legislative News, Studies and Analysis. Available from: http://www.ncsl.org/research/health/preventio $\mathrm{n}$-of-prescription-drug-overdose-and-abuse. aspx\#1

[5] House Bill 93. Available from: https://www.legislature.oh io.gov/legislation/legislation-summary?id=GA132-H B-93

[6] Jones CM, Logan J, Gladden RM, et al. Demographic and substance use trends among heroin users - United States, 2002-2013. MMWR.
2015; 64(26): 719-725. PMid:26158353.

[7] Bride BE, Macmaster SA, Morse SA, et al. A Comparison of Opioid and Nonopioid Substance Users in Residential Treatment for Co-Occurring Substance Use and Mental Disorders. Social Work in Public Health. 2016; 31(7): 678-687. PMid:27366988. https : //doi.org/10.1080/19371918.2016.1188738

[8] McLellan AC. The Addiction Severity Index at 25: Origins, contributions and transitions. The American Journal on Addictions. 2006; 15: 113-124. PMid:16595348. https://doi .org/10.1080/1055 0490500528316

[9] Stanton MD, Todd TC, Heard DB, et al. Heroin Addiction as a Family Phenomenon: A New Conceptual Model. The American Journal of Drug and Alcohol Abuse. 1978; 5(2): 125-150. PMid:371388. https://doi.org/10.3109/00952997809027993

[10] Link B, Struening E, Rahav M, et al. On Stigma and Its Consequences: Evidence from a Longitudinal Study of Men with Dual Diagnoses of Mental Illness and Substance Abuse. Journal of Health and Social Behavior. 1997; 38(2): 177-190. PMid:9212538. https : //doi.org/10.2307/2955424 